\title{
SISTEM INFORMASI DISPOSISI ONLINE DIDUKUNG TEKNOLOGI SHORT MESSAGE SERVICE
}

\author{
Tining Haryanti ${ }^{1)}$ \\ 1), Program Studi Teknik Komputer, Fakultas Teknik, Universitas Muhammadiyah Surabaya \\ Jl SutorejoNo. 59, Surabaya \\ Email : tining.haryanti@ft.um-surabaya.ac.id ${ }^{1)}$
}

\begin{abstract}
Abstrak
Disposisi surat merupakan salah satu tahapan pada distribusi perintah berdasarkan level jabatan. Permasalahan terjadi apabila disposisi terlewatkan karena salah satu pihak tidak berada ditempat/ keluar kantor sehingga instruksi kerja terhenti/ tidak terlaksana secara optimal. Sistem informasi pengarsipan secara umum berbasis web sehingga bisa diakses secara real time dimanapun pihak berada selama ada koneksi internet. Pemanfaatan SMS gateway dalam sistem ini menyesuaikan dengan kebutuhan perusahaan X yang memiliki jangkauan kerja di kelautan dan pinggiran dengan mengabaikan kuota dan jaringan internet untuk akses disposisi perintah kerja. Disposisi yang dilakukan melalui sms ini akan terupdate secara otomatis pada sistem. Pihak yang terkait tidak perlu mengakses sistem online di web apabila disposisi telah dilakukan melalui SMS. Dengan adanya sistem informasi disposisi online didukung Teknologi SMS diharapkan instruksi kerja pada perusahaan X sesuai dengan disposisi bisa dijalankan dengan optimal.
\end{abstract}

Kata Kunci : disposisi, online, web, sms

\section{Abstract}

Mail disposition is astages in command distribution based on job level. Problem exist when disposition is missed due to one party's unavailability in his/her office so that work instruction stops/ inefficiently executed. Information sistem archiving generally is done through web so that it can be accessed in real time wherever there is internet connection available. The usage of SMS gateway in the sistem is adjusted to what $X$ company needs which has the coverage in both seas and rural places by ignoring quota and internet network to access work command disposition. Disposition done through this SMS will automatically be updated in sistem. The related party will no longer need to access web online sistem if the disposition has already been done through SMS. By the existence of online disposition information sistem assisted by SMS technology it is expected that work instruction according to disposition in company $X$ can be run optimally.

Keywords : disposisi, online, web, sms

\section{Pendahuluan}

Disposisi merupakan pendapat seorang pejabat mengenai urusan yang termuat dalam suatu surat dinas, yang langsung dituliskan pada surat yang bersangkutan atau pada lembar khusus [1]. Proses disposisi dapat dilakukan secara berjenjang. Sebagai contoh disposisi suatu pekerjaan dapat diberikan oleh pejabat tertinggi pada beberapa pejabat dengan alur disposisi pertama dapat dilanjutkan ke pejabat berikutnya apabila pejabat yang sebelumnya sudah menyetujui, dan seterusnya. Proses pekerjaan terhambat dikarenakan pihak yang terkait disposisi tidak ditempat. Waktu tunggu proses disposisi atau peralihan disposisi menjadikan pelaksanaan pekerjaan tidak optimal karena tidak pada kondisi ideal. Disposisi online menjadi salah satu solusi apabila pihak terkait tidak ditempat. Namun masalah baru muncul kembali 
apabila pihat terkait disposisi berada di lokasi yang tidak terjangkau dengan jaringan internet/ kuota. Permasalahan ini muncul secara spesifik pada perusahaan $X$ yang memiliki jangkaun rutin pekerjaan didaerah pesisir dan laut/ perbatasan. Pada beberapa keadaan signal internet tidak memadai. Dengan pemanfaatan teknologi SMS untuk melakukan disposisi sekaligus sebagai reminder apabila ada disposisi, diharapkan dapat mengatasi permasalahan tersebut

Beberapa penelitian telah dilakukan berkaitan dengan sistem informasi pengarsipan. Penelitian yang dilakukan oleh [2] dengan judul Rancang Bangun Sistem Informasi Disposisi Surat Masuk Dinas Pendidikan Kota Semarang. Hasil penelitian adalah sistem informasi yang dibangun merupakan sistem yang praktis dan efektif untuk diterapkan sebagai pengganti sistem pengelolaan surat masuk dan disposisinya di Disdik Kota Semarang. Perbedaan pada penelitian ini adalah belum adanya dukungan teknologi SMS baik untuk menggantikan proses disposisi pada saat tidak bisa mengakses web maupun sebagai reminder adanya disposisi pada pihak terkait. Penelitian selanjutnya yang dilakukan oleh [3] dengan judul sistem informasi pelayanan surat-surat akademik Menggunakan sms gateway di Fakultas Ilmu Budaya Universitas Brawijaya. Hasil dari penelitian ini adalah membantu proses permintaan surat-surat akademik mahasiswa melalui web dan form sms gateway dari mahasiswa. Perbedaan dengan perancangan Sistem Informasi disposisi online didukung SMS ini adalah penggunaan disposisi online secara parallel baik dengan web maupun SMS. Sehingga apabila disposisi telah dilakukan melalui SMS, secara otomatis disposisi tersebut bisa diteruskan pada pihak selanjutnya tanpa harus mengakses disposisi online melalui web. Berdasarkan hasil observasi di lapangan, proses disposisi pada perusahaan $\mathrm{X}$ masih dilakukan secara manual, yaitu dengan lembar disposisi. Setiap ada proses disposisi, petugas kesekretariatan melakukan kontrol terhadap jalannya proses disposisi tersebut. Apabila pihak terkait tidak di tempat, proses disposisi terhenti atau diwakilkan pada pihak yang ditunjuk. Tingginya penugasan diluar kantor menjadi salah satu penyebab pihak terkait disposisi tidak ada ditempat. Penugasan karyawan di perusahaan $\mathrm{X}$ sebagian besar didaerah pinggiran/perbatasan dan laut/ lepas pantai yang dalam beberapa kasus tidak terjangkau jaringan internet. Aplikasi ini dibuat agar dapat membantu proses disposisi online yang didukung SMS baik sebagai pengganti disposisi online pada web sekaligus sebagai reminder pihak terkait yang mendapatkan disposisi. Diharapkan dengan penerapan sistem ini, kegiatan operasional perusahaan dapat dilakukan dengan optimal.

\section{Dasar teori}

Disposisi merupakan petunjuk singkat tentang tindak lanjut (penyelesaian) terhadap suatu urusan atau surat masuk[4]. Pada perusahaan yang tingkat mobilitas karyawannya tinggi memerlukan sistem yang dapat mengakomodir percepatan disposisi. Penugasan pihak yang terkait dengan disposisi terkadang tidak memungkinkan untuk melakukan akses internet, sehingga diperlukan dukungan teknologi yang dapat menggantikan. Teknologi yang digunakan pada penelitian ini adalah sms gateway. Aplikasi SMS Gateway adalah sebuah perangkat lunak yang menggunakan bantuan komputer dan memanfaatkan teknologi seluler yang diintegrasikan guna mendistribusikan pesan pesan yang dipadukan lewat sistem informasi melalui media SMS yang ditangani oleh jaringan seluler[5]. Pemilihan teknologi SMS Gateway sebagai pengganti jalannya sistem apabila akses internet tidak memadai atau karena suatu pekerjaan tidak memungkinkan mengakses website. Pemodelan pada perancangan sistem ini menggunakan Unified Modelling Language. Unified Modeling Language (UML) adalah bahasa spesifikasi standar yang dipergunakan untuk mendokumentasikan, menspesifikasikan dan membangun perangkat lunak. UML merupakan metodologi dalam mengembangkan sistem berorientasi objek dan juga merupakan alat untuk mendukung pengembangan sistem. [6] 


\section{Metodologi Penelitian}

Penelitian ini merupakan penelitian observasional dengan analisa penelitian bersifat kualitatif deskriptif dengan metode pengembangan sistem prototyping. Model ini selanjutnya terus dikembangkan sampai sesuai dengan kebutuhan pengguna. Data yang digunakan dalah data yang bersumber dari wawancara, observasi dan data sekunder dari perusahaan X. Aplikasi yang digunakan pada sistem ini adalah PHP dengan database MySQL. Pemilihan website dengan client server karena tingginya operasional pengarsipan dan disposisi online sehingga memerlukan server tersendiri [7]. MySQL digunakan sebagai database pada sistem ini sesuai dengan daya tampung database yang dapat dikelola oleh Mysql [7].

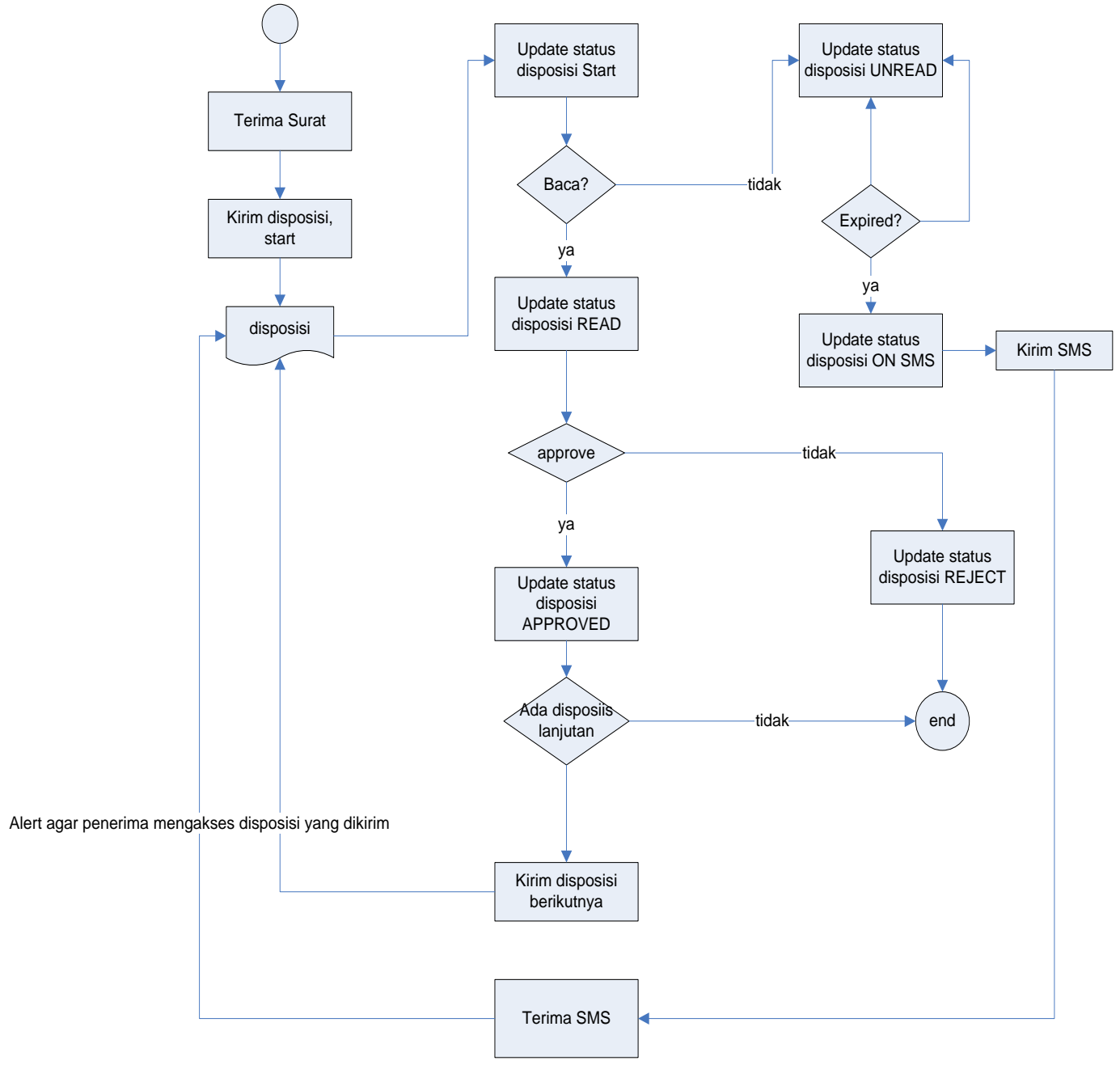

Gambar 1. Workflow Disposisi Online

Aplikasi SMS Gateway adalah sebuah perangkat lunak yang menggunakan bantuan komputer dan memanfaatkan teknologi seluler yang diintegrasikan guna mendistribusikan pesan yang dipadukan lewat sistem informasi melalui media SMS yang ditangani oleh jaringan seluler. Pemanfaatan SMS gateway dalam perancangan sistem ini menyesuaikan dengan kebutuhan lapangan yaitu perusahaan $X$ dengan mengabaikan kuota/ jaringan internet untuk akses informasi. Penelitian ini diawali dengan identifikasi sistem disposisi perusahaan X. Identifikasi dilakukan dengan observasi dan wawancara pada petugas kesekretariatan yang melakukan kontrol terhadap disposisi dan karyawan sebagai pihak terkait/pelaku disposisi. Setelah tahapan identifikasi dilakukan analisis untuk mengetahui kekurangan yang ada pada 
sistem disposisi perusahaan X. Dari analisis tersebut dicari alternatif solusi untuk menyelesaikan masalah yang ada pada disposisi perusahaan X. Perancangan sistem informasi disposisi online didukung teknologi SMS dapat digambarkan pada gambar 1.

Usulan sistem tersebut diharapkan dapat memenuhi kebutuhan perusahaan $\mathrm{X}$ dalam proses disposisi online didukung teknologi SMS. Teknologi SMS dapat difungsikan untuk menggantikan proses disposisi online (Approved, rejected) melalui website dan sebagai reminder pada pihak terkait disposisi. Melalui reminder SMS, pihak yang mendapatkan disposisi mengetahui untuk segera melakukan proses disposisi tersebut. Dengan demikian diharapkan proses disposisi dapat dilakukan tanpa terkendala kuota maupun koneksi internet. Sebelum membuat aplikasi sesuai dengan usulan sistem, dipersiapkan perancangan Sistem. Alat bantu pemodelan yang digunakan pada perancangan sistem menggunakan Unified Modelling Language. Pemodelan class yang diterapkan pada sistem ini terdiri dari Use Case View dan Logical View.

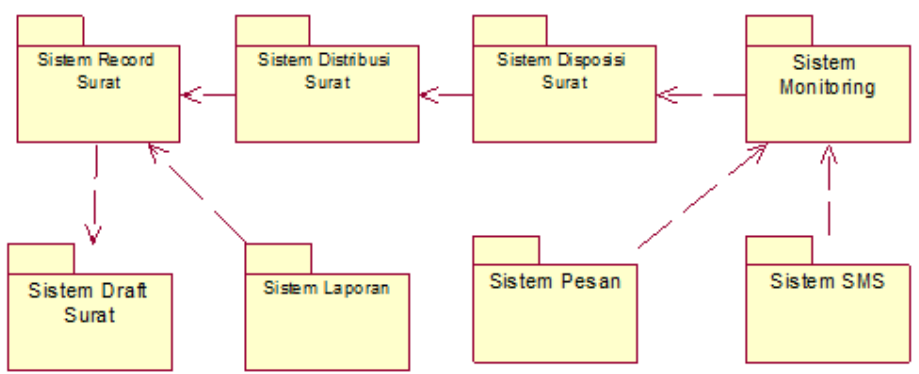

Gambar 2. Use Case View Sistem Informasi Disposisi Online didukung SMS

Paket paket Use Case ini dibuat karena kompleksitas Use Case yang ada sehingga dipisahkan dalam package. Business Use Case Model menggambarkan proses manual pada aplikasi. Package tersebut direalisasikan dengan sistem realisasi sebagai berikut :

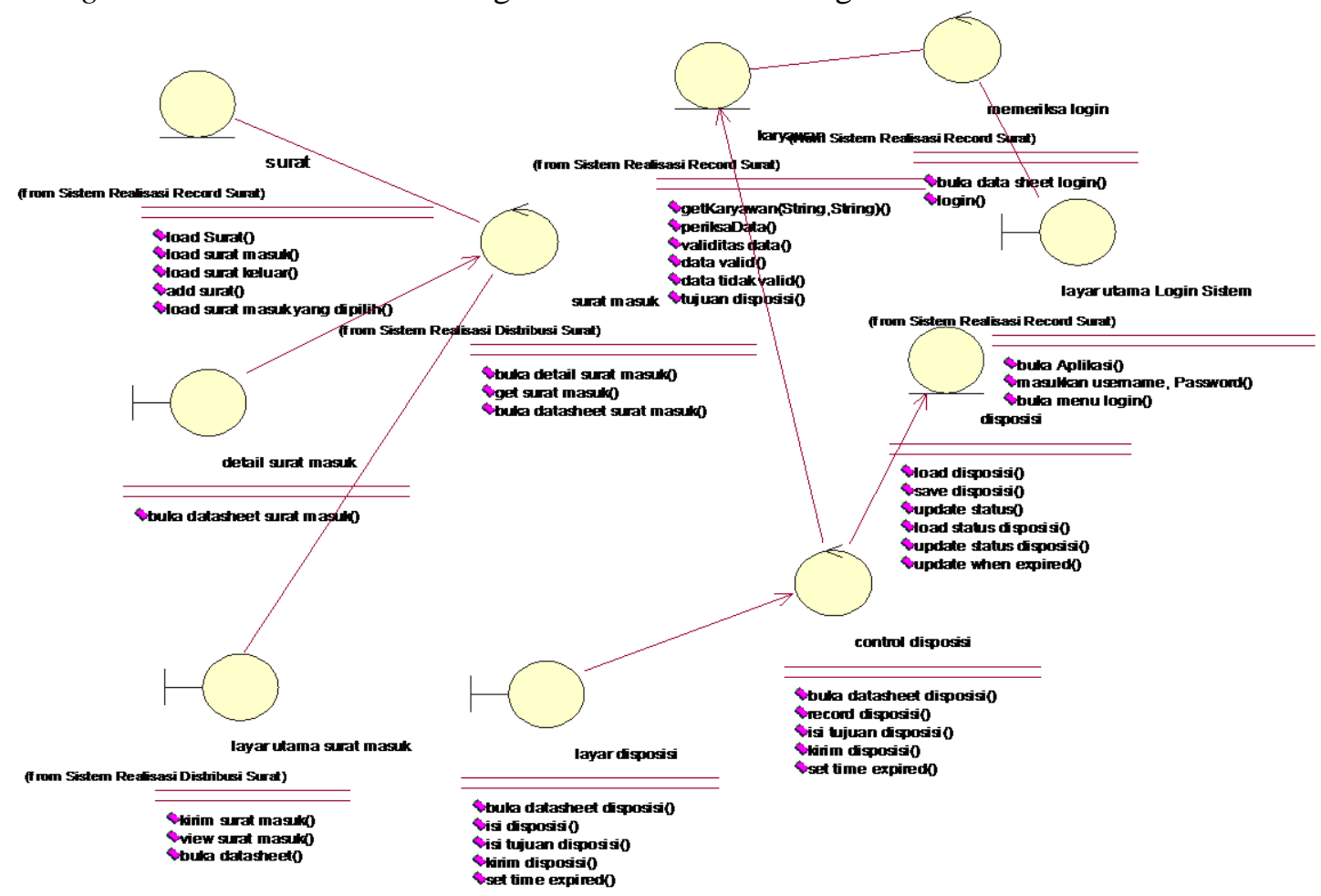




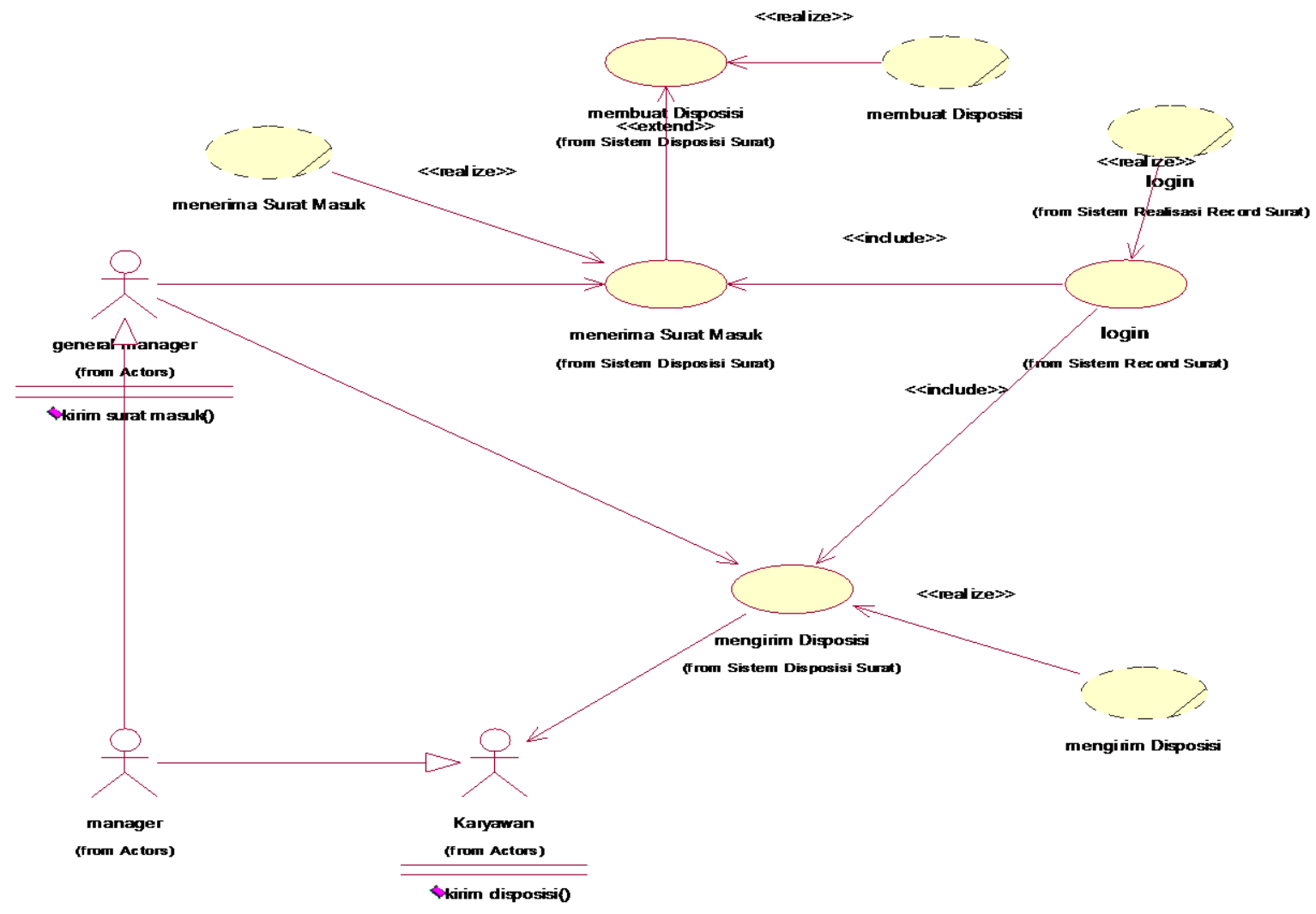

Gambar 3. Sistem Realisasi Disposisi

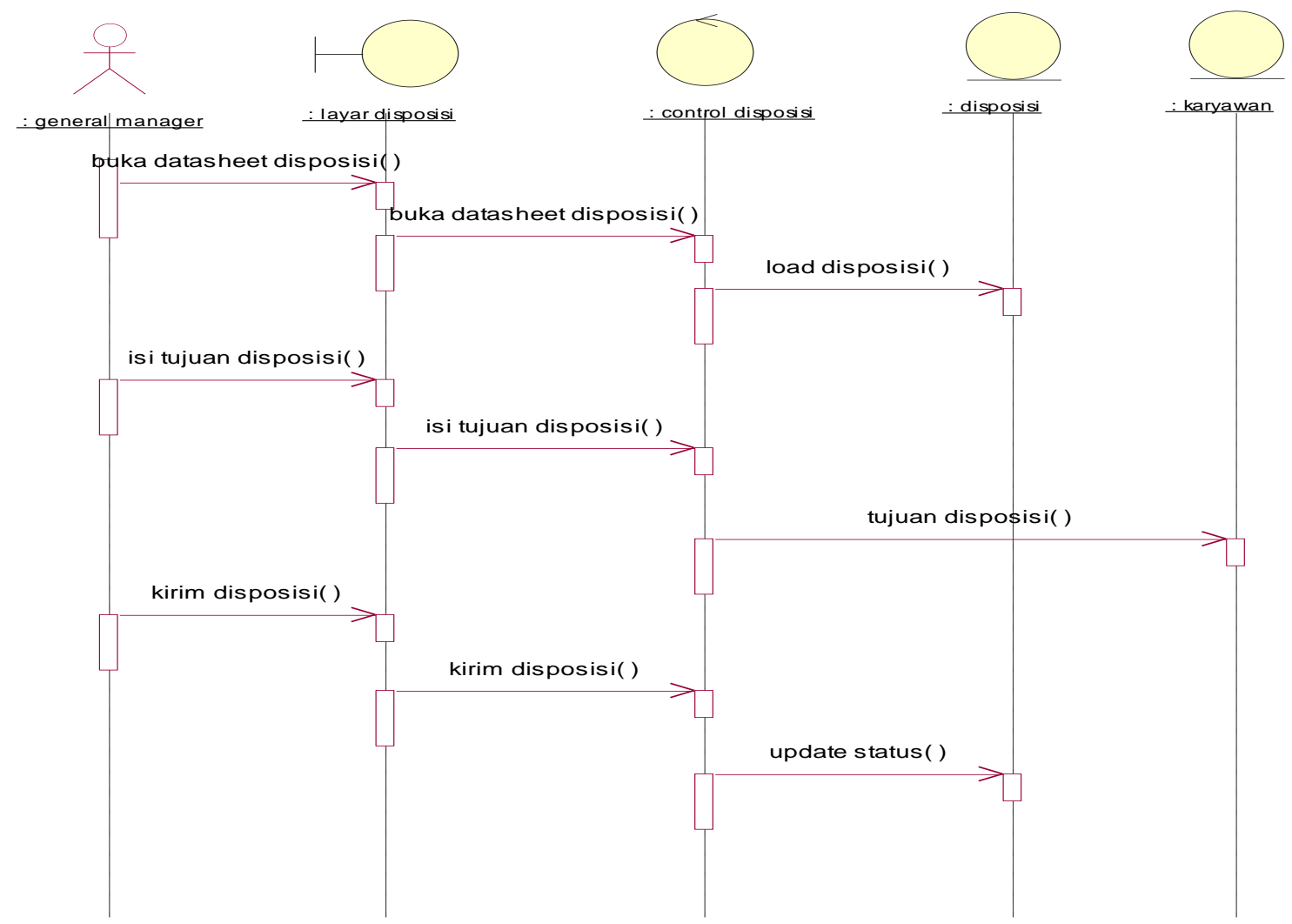

Gambar 4. Sequence Pengiriman Disposisi 


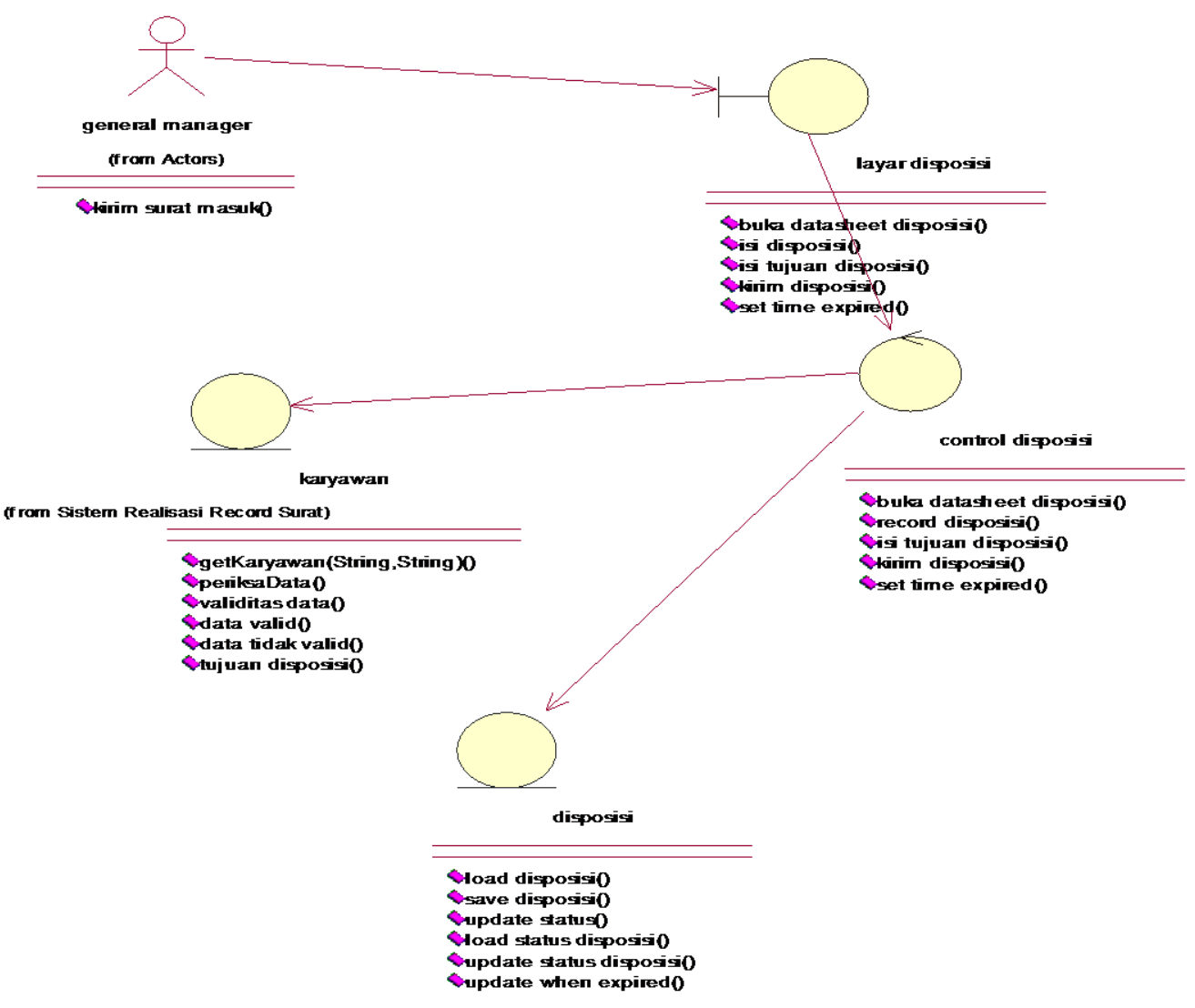

Gambar 5. Hubungan Class Disposisi

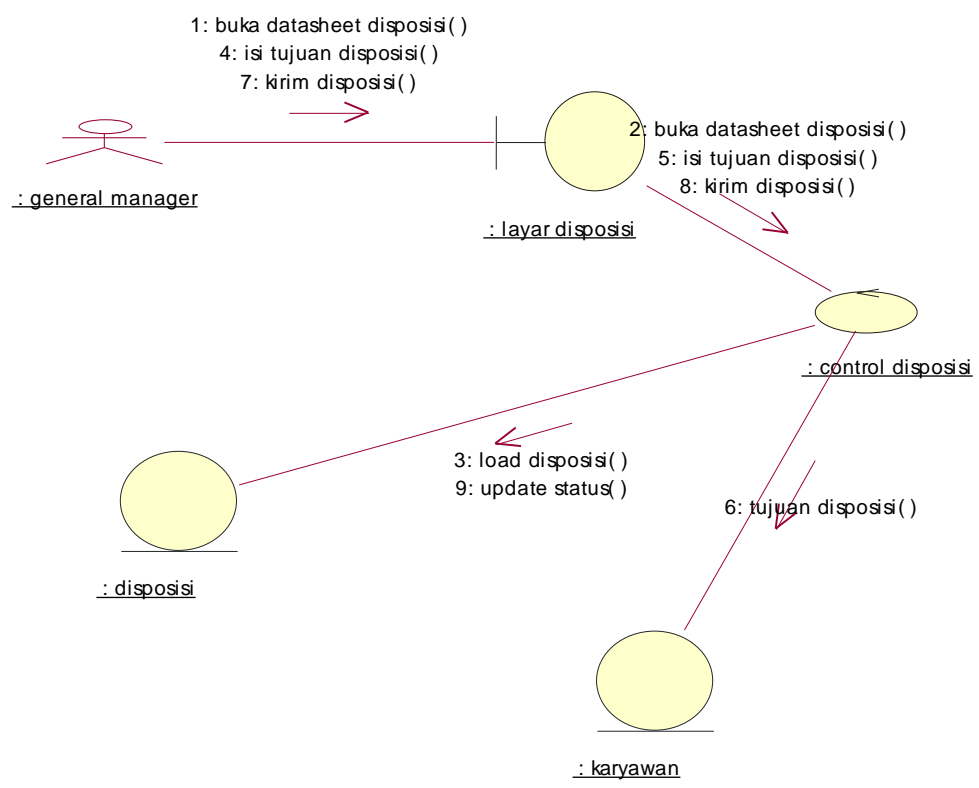

Gambar 6. Collaboration Diagram Disposisi

\section{Pengujian dan Pembahasan}

Penelitian ini menghasilkan sebuah aplikasi Sistem Informasi Disposisi Online didukung Teknologi SMS yang dipergunakan untuk sistem disposisi di perusahaan X. Aplikasi ini bertujuan sebagai solusi proses disposisi online yang sebelumnya dilakukan secara manual 
sehingga proses disposisi terhenti/terhambat apabila pelaku disposisi tidak ditempat. Pemanfaatan teknologi SMS sebagai salah satu solusi proses disposisi online tetap bisa dijalankan tanpa terkendala kuota/ internet. Tabel yang digunakan pada aplikasi ini diantaranya Tabel Departemen, Disposisi, Draft, Inbox, Jabatan, Jenis Surat, Karyawan, Lampiran Surat, Mitra, Notifikasi, Pesan, Surat dan user level. Struktur tabel disposisi sebagaimana berikut

Tabel 1. Disposisi

\begin{tabular}{|c|c|c|c|}
\hline Field & Type & Constraint & Description \\
\hline Kode_Disp & $\operatorname{varchar}(10)$ & Primary Key & Kode disposisi \\
\hline Kode_Surat & varchar(10) & & Kode Surat \\
\hline No_Asal & $\operatorname{varchar}(10)$ & & Nomor Asal \\
\hline No_Tujuan & $\operatorname{varchar}(10)$ & & Nomor Tujuan \\
\hline Level_Disp & $\operatorname{int}(11)$ & & Level Disposisi \\
\hline Jenis_Disp & enum('FYA', 'FYI', 'Circle') & & Jenis Disposisi \\
\hline Isi_Disp & $\operatorname{varchar}(250)$ & & Isi Disposisi \\
\hline Catatan_Disp & $\operatorname{varchar}(250)$ & & Catatan Disposisi \\
\hline Baca_Disp & enum('U', 'R') & & Baca Disposisi \\
\hline App_Disp & enum('U', 'A', 'R') & & Status Disposisi \\
\hline Tgl_Disp & datetime & & Tanggal Disposisi \\
\hline LTime_Disp & $\operatorname{int}(3)$ & & Live Time Disposisi \\
\hline Exp_Disp & datetime & & ExpiredTime \\
\hline Stat_Disp & enum('D', 'S', 'O') & & Status Workflow \\
\hline
\end{tabular}

Tabel Disposisi berfungsi untuk menyimpan data disposisi. Tabel ini memiliki primary key: Kode_Disp. Field Jenis_Disp berisi pilihan jenis disposisi yaitu FYA, FYI dan Circle. Field Baca_Disp memiliki 2 pilihan isian yaitu U untuk unread dan R untuk Read. FieldApp_Disp adalah status disposisi berisi 3 status yaitu A untuk Approve, U untuk Unapproved dan R untuk reject. Status Workflow tertulis D untuk draft, S untuk Start dan O untuk On SMS. Akses sistem informasi disposisi Online didukung Teknologi SMS diawali dari form login dan menuju halaman utama ditunjukkan pada gambar 7.

Pada Menu Link terdapat banyak link menu yang disediakan untuk user, semua menu tampil pada akses Admin, selain admin menu yang ditampilkan sesuai dengan previllage nya. Menu yang ada pada aplikasi antara lain Departemen, Permission berisi tentang hak akses yang dimiliki/ setting oleh pengguna sistem, menu ini hanya bisa diakses oleh administrator, Jabatan, karyawan, Mitra Usaha dll. Terdapat menu Inbox berisi data inbox yang ada pada engine SMS. Berfungsi untuk menampung SMS yang ada pada inbox engine agar tidak penuh sehingga engine selalu dalam keadaan available saat digunakan untuk pengiriman SMS. Menu Inbox bersifat maintenance terhadap engine sehingga hanya bisa diakses oleh admin. Dan SMS Notifikasi, berisi sms notifikasi yang memberi report pada sistem mengenai proses disposisi yang telah mengalami expired time sehingga proses web beralih pada engine. Menu ini juga dapat dimanfaatkan sebagai SMS broadcast. Setelah aplikasi selesai dibangun, aplikasi diterapkan pada perusahaan tempat survey dilakukan. Pengisian angket pengimplementasian sistem sebagai output tercapai tidaknya tujuan sistem secara kualitatif. 


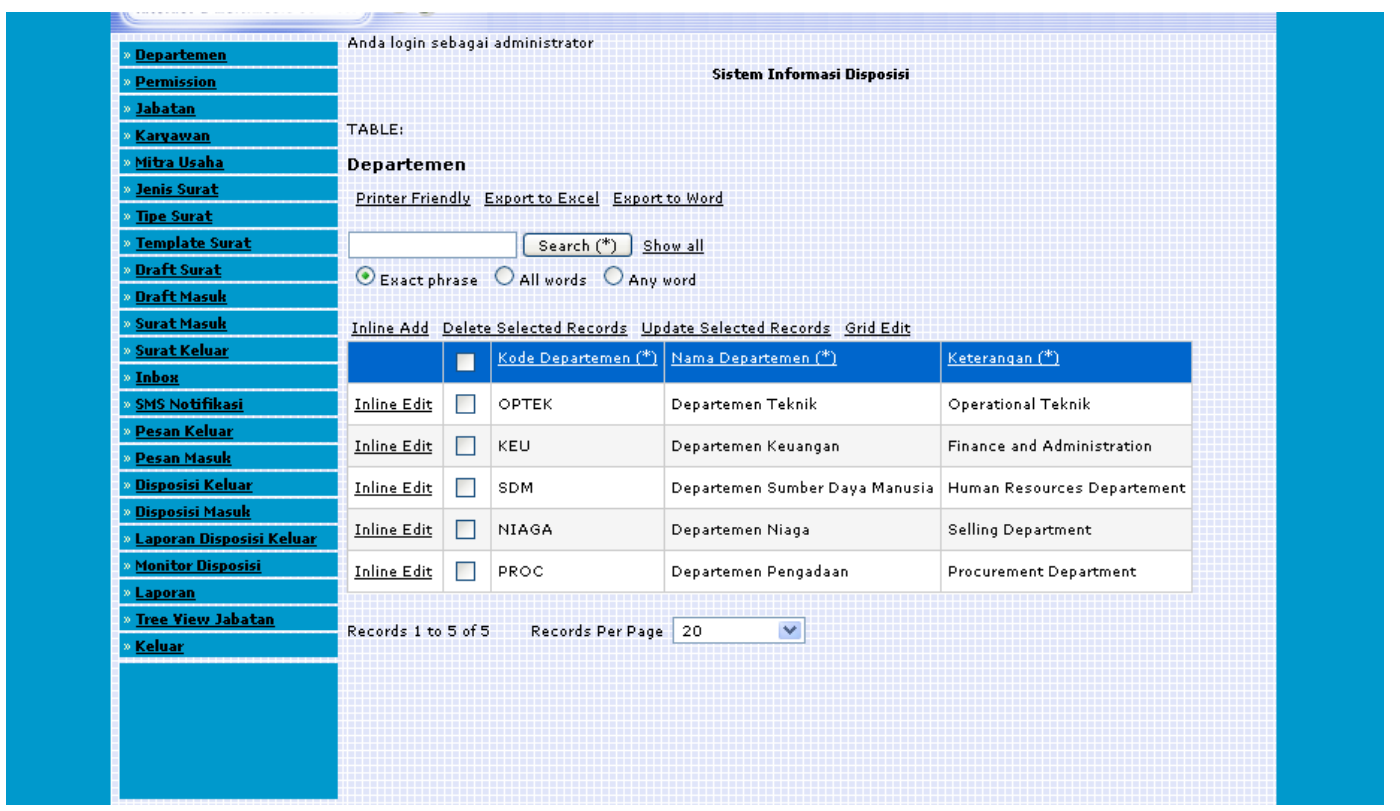

Gambar 7. Tampilan Aplikasi

Tabel 2. Uji Coba

\begin{tabular}{|r|l|c|c|c|}
\hline \multirow{2}{*}{ No Uji Coba } & \multicolumn{2}{c|}{ Proses } & \multirow{2}{*}{ Efektivitas } \\
\cline { 3 - 4 } & & Sebelum & Sesudah & \\
\hline 1 & Proses Disposisi & 48 jam & 1 jam & $98 \%$ \\
\hline 2 & Pencarian data & 15 menit & 2 menit & $87 \%$ \\
\hline 3 & Pembuatan Laporan Disposisi & 15 menit & 2 menit & $87 \%$ \\
\hline 4 & Jumlah error pencarian dokumen disposisi/ tidak ditemukan & $10 \%$ & $0 \%$ & $100 \%$ \\
\hline \multicolumn{3}{|c|}{ Rata rata Efektivitas } & $93 \%$ \\
\hline
\end{tabular}

\section{Kesimpulan}

Keterlibatan penggunaan teknologi dalam proses disposisi membantu dalam menyelesaikan masalah keterlambatan proses disposisi yang ada pada perusahaan X. Dengan adanya sistem informasi disposisi online didukung teknologi Short Message Service, kendala proses disposisi karena pelaku disposisi tidak berada ditempatnya dapat diatasi. Pemanfaatan teknologi SMS pada proses disposisi baik sebagai pengganti akses melalui web maupun pengingat adanya disposisi menjadi solusi pelaku disposisi tanpa ketergantungan kuota dan jaringan internet. Hal ini diperlukan karena perusahaan X lebih banyak menugaskan karyawan/ pelaku disposisi pada daerah pinggiran/ laut yang sering terkendala jaringan. Berdasarkan uji coba sistem didapatkan perbandingan sebelum dengan sesudah penggunaan sistem yaitu 93\%. Dengan penerapan sistem disposisi online didukung teknologi SMS permasalahan pada proses disposisi pada perusahaan $\mathrm{X}$ dapat teratasi dan diharapkan proses pelaksanaan pekerjaan dapat berjalan optimal.

\section{Daftar Pustaka}

[1] https://kbbi.web.id/disposisi , akses 1 September 2018

[2] Amar Basir, Hari Wibawanto, "Rancang Bangun Sistem Disposisi Surat Masuk Dinas Pendidikan Kota Semarang", Universitas Negeri Semarang, Edu Komputika Journal Vol. 1, No. 2, pp. 33-42, 2014 
[3] Mukhammad Farid, Dinny Wahyu Widarti, "Sistem Informasi Pelayanan Surat-surat Akademik menggunakan SMS Gateway di Fakultas Ilmu Budaya Universitas Brawijaya", Jurnal Dinamika DotCom, Vol. 7, No. 1 pp. 7-20, 2016.

[4] Vironica, Ariedan Sukadi, "Rancang Bangun Aplikasi Pengelolaan Surat Masuk Dan Surat Keluar Pada Sekolah Menengah Pertama Negeri2 Nawangan". Speed Journal, Vol. 11, No. 1, pp 34-41, 2014.

[5] P. M. Wikma, "SMS GATEWAY SMS Gateway adalah teknologi mengirim, menerima dan bahkan mengolah sms melalui komputer dan sistem komputerisasi (software)," 2014. [Online].Available:http://www.academia.edu/4080794/SMS_GATEWAY_SMS_Gatew ay_adalah_teknologi_mengirim_menerima_dan_bahkan_mengolah_sms_melalui_komp uter_dan_sistem_komputerisasi_software. [Accessed 1 September 2018].

[6] Ade Hendini, Pemodelan UML Sistem Informasi Monitoring penjualan dan Stok Barang (Studi Kasus: Distro Zhezha Pontianak), Jurnal Khatulistiwa Informatika, Vol.IV, No.2, pp 107-116, 2016.

[7] David Putra Harsalim, Rinabi Tanamal, "Rancang Bangun Sistem Informasi Administrasi Berbasis Web MenggunakanPHP dan MySQL Pada Yukowina Jaya Motor Warehouse", Jurnal Ilmiah Teknologi Informasi dan Multimedia (TIM), Vol. 2, No. 1, pp $58-69,2012$. 